\title{
Abnormal Activity of the MAPK- and cAMP-Associated Signaling Pathways in Frontal Cortical Areas in Postmortem Brain in Schizophrenia
}

\author{
Adam J Funk ${ }^{*}, 1,2$, Robert E McCullumsmith ${ }^{2}$, Vahram Haroutunian ${ }^{3}$ and James H Meador-Woodruff ${ }^{2,4}$ \\ 'Department of Neurobiology, University of Alabama Birmingham, Birmingham, AL, USA; '2Department of Psychiatry and Behavioral \\ Neurobiology, University of Alabama Birmingham, Birmingham, AL, USA; ${ }^{3}$ Department of Psychiatry, Mount Sinai School of Medicine, New York, \\ NY, USA; ${ }^{4}$ Evelyn F. McKnight Brain Institute, University of Alabama Birmingham, Birmingham, AL, USA
}

Recent evidence suggests that schizophrenia may result from alterations of integration of signaling mediated by multiple neurotransmitter systems. Abnormalities of associated intracellular signaling pathways may contribute to the pathophysiology of schizophrenia. Proteins and phospho-proteins comprising mitogen activated protein kinase (MAPK) and $3^{\prime}-5^{\prime}$-cyclic adenosine monophosphate (cAMP)associated signaling pathways may be abnormally expressed in the anterior cingulate (ACC) and dorsolateral prefrontal cortex (DLPFC) in schizophrenia. Using western blot analysis we examined proteins of the MAPK- and CAMP-associated pathways in these two brain regions. Postmortem samples were used from a well-characterized collection of elderly patients with schizophrenia (ACC $=36$, $\mathrm{DLPFC}=35)$ and a comparison $(A C C=33, \mathrm{DLPFC}=3 \mathrm{I})$ group. Near-infrared intensity of IR-dye labeled secondary antisera bound to targeted proteins of the MAPK- and CAMP-associated signaling pathways was measured using LiCor Odyssey imaging system. We found decreased expression of Rap2, JNKI, JNK2, PSD-95, and decreased phosphorylation of JNKI/2 at TI 83/Y I 85 and PSD-95 at S295 in the ACC in schizophrenia. In the DLPFC, we found increased expression of Rack1, Fyn, Cdk5, and increased phosphorylation of PSD-95 at S295 and NR2B at Y1336. MAPK- and CAMP-associated molecules constitute ubiquitous intracellular signaling pathways that integrate extracellular stimuli, modify receptor expression and function, and regulate cell survival and neuroplasticity. These data suggest abnormal activity of the MAPK- and CAMP-associated pathways in frontal cortical areas in schizophrenia. These alterations may underlie the hypothesized hypoglutamatergic function in this illness. Together with previous findings, these data suggest that abnormalities of intracellular signaling pathways may contribute to the pathophysiology of schizophrenia.

Neuropsychopharmacology (2012) 37, 896-905; doi:I0.1038/npp.20 I 1.267; published online 2 November 20I I

Keywords: schizophrenia; postmortem; signaling; MAPK; cAMP; phosphorylation

\section{INTRODUCTION}

Schizophrenia is a complex psychiatric illness associated with dysregulation of multiple brain neurotransmitter systems (Fatemi and Folsom, 2009; MacDonald and Schulz, 2009; Stilo and Murray, 2010). Although alterations of these neurotransmitter systems, including dopamine, glutamate, GABA, serotonin, and acetylcholine, have led to hypotheses centered on neurotransmitter receptor expression and function as key elements of the pathophysiology of this illness, integration of signaling mediated by multiple neurotransmitter receptors is a critical step in determining the

*Correspondence: Dr AJ Funk, Department of Neurobiology, University of Alabama Birmingham, CIRC 586, $17196^{\text {th }}$ Ave. S. Birmingham, AL 35294-002I, USA, Tel: + I 205996 6356, Fax: + I 205975 4879, E-mail: adamfunk@uab.edu

Received 13 June 201 I; revised 16 September 2011; accepted 22 September 2011 functional consequences of receptor activation (Kyosseva, 2004b; Lang et al, 2007; Laruelle et al, 2003; Lewis and Hashimoto, 2007; Lewis and Moghaddam, 2006; Lowes et al, 2002; Ross et al, 2006; Svenningsson et al, 2004; Sweatt, 2001, 2004; Volk et al, 2010). Accordingly, alterations of signal integration pathways may contribute to the pathophysiology of schizophrenia.

Many neurotransmitter receptors are functionally coupled to protein kinases and/or G-proteins, which modulate cascades of molecules that in turn regulate critical cellular functions (Gardoni et al, 2006; Hosokawa et al, 2006; Krapivinsky et al, 2004; Mauceri et al, 2007; Santucci and Raghavachari, 2008; Song et al, 2004). For example, the mitogen activated protein kinase (MAPK)-associated pathway activates transcription factors related to learning, memory, cell proliferation, and apoptosis. This pathway integrates extracellular stimuli through the phosphorylation of c-Jun N-terminal kinase (JNK), extracellular 
signal-regulated kinase (ERK), p38, and other kinases (Kyosseva, 2004b; Kyosseva et al, 1999; Sweatt, 2001). Similar to the MAPK-associated pathway, $3^{\prime}-5^{\prime}$-cyclic adenosine monophosphate (cAMP)-associated pathways are also coupled to activation of neurotransmitter receptors, and modulate cellular functions through the activation of protein kinase A (PKA), exchange protein activated by cAMP (EPAC), and other molecules (Borland et al, 2009; Cheng et al, 2008; Hochbaum et al, 2008; Ma et al, 2009; Roberson et al, 1999; Sands and Palmer, 2008). Alterations of the MAPK- and CAMP- associated signaling pathways may impact intracellular $\mathrm{Ca}^{++}$levels, neurotransmitter receptors, transcription factors, crosstalk between signaling pathways, and other biological functions critical for neuroplasticity (Gelinas et al, 2008; Reichenberg, 2010; Sands and Palmer, 2008).

In this study, we have examined the hypothesis that intracellular signaling molecules are altered in the frontal cortex in schizophrenia. Using western blot analysis, we measured expression of proteins of the MAPK- and cAMPassociated signaling pathways in the anterior cingulate (ACC) and dorsolateral prefrontal cortices (DLPFC) in samples from a well-characterized collection of postmortem brains from subjects with schizophrenia and a comparison group.

\section{MATERIALS AND METHODS}

\section{Tissue Acquisition and Preparation}

Samples from the ACC and DLPFC were obtained from the Mount Sinai Medical Center brain collection. Patients were diagnosed with schizophrenia using DSM-III-R criteria (Bauer et al, 2008; Davidson et al, 1995; Harvey et al, 1992; Powchik et al, 1998). Each patient had a documented history of psychotic symptoms before the age of 40 , and at least 10 years of hospitalization with a diagnosis of schizophrenia made by two clinicians. Patients were recruited prospectively and underwent extensive antemortem diagnostic and clinical assessment. Exclusions for this study included a history of substance abuse, death by suicide, or coma for more than $6 \mathrm{~h}$ before death. Neuropathological examination revealed no neurodegenerative diseases including Alzheimer's disease in any subjects. Next of kin consent was obtained for each patient (Bauer et al, 2008, 2009, 2010; Funk et al, 2009; Hammond et al, 2010; Oni-Orisan et al, 2008). Schizophrenia and comparison groups were matched for sex, age, $\mathrm{pH}$, and PMI (Table 1). Comparison subjects were selected using a formal blinded medical chart review instrument with no history of psychiatric or neurological disease. The assessment included the CERAD battery, the Clinical Dementia Rating Scale, and the Positive and Negative Syndrome Scale (Powchik et al, 1998). Comparison subjects were also evaluated for dementia and neurodegenerative diseases as well as any history of drug and alcohol abuse (Oni-Orisan et al, 2008). Detailed tables of comparison and schizophrenia subjects (Supplementary Tables 1 and 2) are provided as a comprehensive list of specific demographics for each group.

Samples were obtained at autopsy from the left hemisphere. The ACC was dissected at the level of the genu of the corpus callosum, the DLPFC was dissected from Brodmann areas 9 and 46. Gray matter was dissected from white, and then samples were portioned into $1 \mathrm{~cm}^{3}$ pieces and stored at
Table I Subject Characteristics

\begin{tabular}{lcccc}
\hline Category & \multicolumn{2}{c}{ Comparison group } & \multicolumn{2}{c}{ Schizophrenia } \\
\hline Region & ACC & DLPFC & ACC & DLPFC \\
$\mathrm{N}$ & 33 & 31 & 36 & 35 \\
Sex & $14 \mathrm{~m} / 19 \mathrm{f}$ & $12 \mathrm{~m} / 19 \mathrm{f}$ & $24 \mathrm{~m} / 12 \mathrm{f}$ & $23 \mathrm{~m} / 12 \mathrm{f}$ \\
Tissue $\mathrm{pH}$ & $6.4 \pm 0.2$ & $6.4 \pm 0.2$ & $6.4 \pm 0.3$ & $6.4 \pm 0.3$ \\
PMI (h) & $8.3 \pm 6.8$ & $8.1 \pm 6.9$ & $13.2 \pm 8.0$ & $12.5 \pm 6.6$ \\
Age (years) & $78 \pm 14$ & $78 \pm 14$ & $74 \pm 11$ & $74 \pm 12$ \\
On/off Rx & $0 / 33$ & $0 / 31$ & $25 / 11$ & $24 / 11$ \\
\hline
\end{tabular}

Abbreviations: Off $R \times$, number of patients neuroleptic free at least 6 weeks before death; $O n R x$, number of patients taking antipsychotic medication at time of death; PMI, postmortem interval.

Values presented as means \pm standard deviation.

$-80^{\circ} \mathrm{C}$ until further processing. Tissue was pulverized into a powder using a mortar and pestle with a small amount of liquid nitrogen and stored at $-80^{\circ} \mathrm{C}$. Samples were reconstituted and homogenized in $5 \mathrm{mM}$ Tris- $\mathrm{HCl} \mathrm{pH} \mathrm{7.4,}$ $0.32 \mathrm{M}$ sucrose and a protease inhibitor tablet (Complete Mini, Roche Diagnostics, Mannheim, Germany) using a Power Gen 125 homogenizer (Thermo Fisher Scientific, Rockford, IL) at speed 5 for $60 \mathrm{~s}$. The homogenates were assayed for protein concentration using a BCA protein assay kit (Thermo Scientific), and stored at $-80^{\circ} \mathrm{C}$.

\section{Western Blot Analysis}

Samples for western blot analyses were diluted with ultrapure (Milli-Q A10, Millipore) water and reducing buffer $(6 \times$ solution: $4.5 \%$ sodium dodecyl sulfate (SDS), $15 \%$ $\beta$-mercaptoethanol, $0.018 \%$ bromophenol blue, and $36 \%$ glycerol in $170 \mathrm{mM}$ Tris- $\mathrm{HCl} \mathrm{pH} \mathrm{6.8)} \mathrm{to} \mathrm{a} \mathrm{concentration} \mathrm{of}$ $20 \mu \mathrm{g}$ of protein per $12 \mu \mathrm{l}$ and heated at $70^{\circ} \mathrm{C}$ for $10 \mathrm{~min}$. Samples were then processed in duplicate by SDS-PAGE using Invitrogen (Carlsbad, CA) $4-12 \%$ gradient gels and transferred to PVDF membranes by BioRad semi-dry transblotters (Hercules, CA). The membranes were blocked with LiCor blocking buffer (Lincoln, NE) for $1 \mathrm{~h}$ at room temperature, then probed with primary antisera (Supplementary Table 3 ) diluted in $0.1 \%$ Tween LiCor blocking buffer. The membranes were washed twice for $10 \mathrm{~min}$ each in $0.1 \%$ Tween phosphate buffer solution (PBST) then probed with goat anti-mouse or goat anti-rabbit IR-Dye 670 or $800 \mathrm{cw}$ labeled secondary antisera in $0.1 \%$ Tween, $0.01 \%$ SDS LiCor blocking buffer for $1 \mathrm{~h}$ at room temperature. Washes were repeated after secondary labeling, washing twice for $10 \mathrm{~min}$ in PBST, then placed in water.

Membranes were imaged using a LiCor Odyssey scanner. Boxes were manually placed around each band of interest, which returned near-infrared fluorescent values of raw intensity with intra-lane background subtracted using Odyssey 3.0 analytical software (LiCor, Lincoln, NE).

\section{Data Analysis}

The near-infrared fluorescence value for each protein of interest was normalized to the in-lane value of either valosin containing protein (VCP) or $\beta$-tubulin, and this normalized 
ratio from duplicate lanes was averaged. $\beta$-tubulin was used for the normalization of PSD-95, pS295 PSD-95, pATF-2, and pc-Jun. VCP was used to normalize all other target proteins, to avoid any potential interference in signal because of the molecular weight of $\beta$-tubulin $(55 \mathrm{kDa})$ and proteins of interest (Bauer et al, 2009). We found no changes in raw intensity values for either VCP or $\beta$-tubulin between the schizophrenia and comparison groups, consistent with previous reports (Bauer et al, 2009; Funk et al, 2009; Hammond et al, 2010).

Data were analyzed using Statistica (Statsoft, Tulsa, OK). All dependent measures were determined to have a Gaussian distribution. Correlation analyses were performed to determine associations between the dependent variables and $\mathrm{pH}$, age, and PMI. Sex and antipsychotic medication status were used as grouping variables for secondary analyses. Dependent measures were considered significant when $p<0.05$. One way analysis of covariance (ANCOVA) was used to analyze the data when significant correlations with potential covariates were found, otherwise analysis of variance was used. Post-hoc power analysis of our significant findings (with $\alpha=0.05$ ) in the ACC revealed an average power $(1 \beta)$ of 0.67 , with a range of $0.51-0.77$. The average power of our significant findings in the DLPFC revealed an average power of 0.7 , with a range of $0.62-0.74$.

\section{RESULTS}

\section{MAPK-Associated Signaling Pathway}

ERK1/2, JNK1/2, and p38 are central MAPK signaling proteins (Bogoyevitch et al, 2010; Kyosseva, 2004b; Zarubin and Han, 2005). We found decreased expression in the ACC in schizophrenia of JNK1 $(\mathrm{F}(1,62)=4.1, p=0.047)$ and JNK2 $(\mathrm{F}(1,62)=7.35, p=0.009)$. We found no changes in ERK1/2 or p38 in either cortical region (Table 2). We also measured the phosphorylation states of these proteins, and found a decrease in the dual phosphorylation state of JNK1/2 at T183/ Y185 $(\mathrm{F}(1,60)=7.46, p=0.008)$ in the ACC in schizophrenia, but no change in the DLPFC (Table 2). We did not find changes in phosphorylated ERK1/2 in either region (Table 2). We were unable to detect and quantify phosphorylated p38.

\section{Downstream Targets of MAPKs}

Dually phosphorylated JNK is a proxy for JNK activity (Davis, 1999; Ip and Davis, 1998; Minden et al, 1994). Our finding of decreased phosphorylation of JNK $1 / 2$ in the ACC led us to measure the phosphorylation state of three downstream targets of JNK: c-Jun, ATF-2, and PSD-95. We found no changes in phosphorylated forms of either c-Jun or ATF-2 in the ACC (Table 2). However, phosphorylation of PSD-95 at S295 was decreased in the ACC $(\mathrm{F}(1,64)=6.8, p=0.01)$ and increased in the DLPFC $(\mathrm{F}(1,48)=7.09, p=0.01)$. We also found decreased levels of total PSD-95 protein expression in the ACC (Table 2).

\section{cAMP- Associated Signaling Pathway}

EPAC1 and EPAC2 are activated by cAMP and are guanine exchange factors of Rap (Borland et al, 2009; Cheng et al, 2008). Therefore, we examined EPAC1 and EPAC2
Table 2 Statistical Analyses of Dependent Variables

\begin{tabular}{|c|c|c|c|}
\hline Protein & $\mathbf{F}$ & d.f. & $p$ \\
\hline \multicolumn{4}{|l|}{ ACC } \\
\hline JNK I & 4.10 & 1,62 & 0.05 \\
\hline JNK2 & 7.35 & 1,62 & 0.01 \\
\hline ERKI & 0.38 & 1,58 & 0.54 \\
\hline ERK2 & 0.14 & 1,56 & 0.71 \\
\hline p38 & 1.16 & 1,67 & 0.28 \\
\hline pTI83/YI85 JNKI/2 & 7.46 & 1,60 & 0.01 \\
\hline pT202/Y204 ERKI/2 & 1.77 & 1,59 & 0.19 \\
\hline Rap I & 0.48 & 1,60 & 0.49 \\
\hline Rap2 & 4.64 & 1,61 & 0.04 \\
\hline EPACI & 0.01 & 1,67 & 0.95 \\
\hline EPAC2 & 0.48 & 1,46 & 0.49 \\
\hline PSD-95 & 6.10 & 1,64 & 0.02 \\
\hline pS295 PSD-95 & 6.80 & 1,64 & 0.01 \\
\hline pATF-2 & 2.17 & 1,50 & 0.15 \\
\hline pc-Jun & 0.01 & 1,61 & 0.98 \\
\hline Cdk5 & 0.41 & 1,65 & 0.52 \\
\hline Rackl & 0.80 & 1,60 & 0.37 \\
\hline Racl & 0.85 & 1,67 & 0.36 \\
\hline Fyn & 0.48 & 1,65 & 0.49 \\
\hline \multicolumn{4}{|l|}{ DLPFC } \\
\hline ERKI/2 & 0.03 & 1,54 & 0.87 \\
\hline p38 & 0.39 & 1,52 & 0.53 \\
\hline $\mathrm{p} T \mid 83 / Y 185$ JNKI/2 & 1.39 & 1,54 & 0.24 \\
\hline pT202/Y204 ERKI/2 & 1.15 & 1,52 & 0.29 \\
\hline Rap I & 0.53 & 1,60 & 0.47 \\
\hline Rap2 & 0.24 & 1,54 & 0.63 \\
\hline pS295 PSD-95 & 7.09 & $\mathrm{I}, \mathbf{4 8}$ & 0.01 \\
\hline pYI336 NR2B & 4.50 & 1,57 & 0.04 \\
\hline Cdk5 & 6.70 & $\mathrm{I}, 47$ & 0.01 \\
\hline Rack I & 5.93 & 1,53 & 0.02 \\
\hline Racl & 0.71 & 1,53 & 0.40 \\
\hline Fyn & 5.04 & 1,55 & 0.03 \\
\hline PKA & 0.07 & 1,60 & 0.80 \\
\hline
\end{tabular}

Bold lines indicate significant differences between patients with schizophrenia and comparison subjects $(\alpha=0.05)$. ANOVA was used for statistical analyses except for PT202/Y204 ERKI/2, PYI336 NR2B, RapI, and PKA of the DLPFC, where ANCOVA was used.

expression in the ACC and found no changes in schizophrenia (Table 2). Rap2 expression was decreased $(\mathrm{F}(1,61)=$ $4.64, p=0.035)$ in the ACC in schizophrenia, with no change in the DLPFC (Table 2). There was no change in Rap1 in schizophrenia in either region (Table 2). We also assayed the catalytic forms of PKA, which are activated by cAMP. We found no change in the catalytic forms of PKA in schizophrenia (Table 2).

\section{Signaling Downstream of PKA Activation}

We next examined the expression of two downstream targets of PKA activation, Rack1 and Fyn, which converge 
upon conserved intracellular signaling molecules mentioned above (Thornton et al, 2004; Yaka et al, 2002). Rack1 $(\mathrm{F}(1,53)=5.9, p=0.018)$ and $\mathrm{Fyn}(\mathrm{F}(1,54)=4.1, p=0.049)$ were increased in the DLPFC in schizophrenia, but not in the ACC (Table 2). NR2 subunits are phosphorylated by Fyn and other Src family kinases (Dunah et al, 2004; GoebelGoody et al, 2009; Yaka et al, 2002). We therefore examined the phosphorylation of NR2B at Y1336 $(\mathrm{F}(1,57)=4.5$, $p=0.038)$, which was increased in the DLPFC in schizophrenia (Table 2). Additional protein-protein interactions can modulate PSD-95-NR2B association and localization (Hawasli et al, 2007; Kim et al, 2007; Morabito et al, 2004; Xie et al, 2007a,b; Zhang et al, 2008). Accordingly, we determined the expression of two candidate proteins that modulate such associations, Racl and Cdk5. We found increased Cdk5 in the DLPFC $(\mathrm{F}(1,47)=6.7, p=0.013)$, but not in the ACC. There was no change in Racl in either region (Table 2 ).

\section{Secondary Analyses}

Sex and antipsychotic medication status were used as grouping variables for secondary analyses. This cohort contains both male and female subjects, and in an effort to control for sex differences we performed an ANOVA with sex as the grouping variable when analyzing our dependent measures. No significant changes were detected between male and female subjects in either comparison or schizophrenia groups (data not shown). Additionally, we analyzed the effect of antipsychotic medication on each of our dependent measures by using medication status (ON vs OFF antipsychotics $>6$ weeks before death) as a grouping variable. Post-hoc analyses showed no significant changes because of the medication status for any dependent measure (data not shown).

\section{DISCUSSION}

In this study, we examined the expression of a series of proteins in the MAPK- and CAMP-associated signaling pathways in the ACC and DLPFC in schizophrenia. Decreased expression of Rap2, JNK1, JNK2, pT183/Y185 JNK1/2, and pS295 PSD-95 was found in ACC (Figure 1). These proteins comprise a MAPK-associated signaling pathway that integrates information from many neurotransmitter receptors implicated in schizophrenia (Figure 3). On the other hand, in the DLPFC we found increased expression of Cdk5, Rack1, Fyn, pS295 PSD-95, and pY1336 NR2B (Figure 2). These cAMP-associated signaling proteins and targets integrate information from neurotransmitter receptors (Figure 3 ). The proteins in these two pathways are critical for the integration of neurotransmission from diverse systems often implicated in the pathophysiology of schizophrenia. These findings may be representative of widespread signaling deficits, which universally affect all CNS cell types and regions.

Signal integration from multiple neurotransmitter receptors is essential for the modulation of learning, memory, and complex behavior (Svenningsson et al, 2004; Sweatt, 2001, 2004). Perhaps the most well-characterized central regulatory molecule known to influence these processes is dopamine-and-cAMP-regulated-neuronal-phosphoprotein a
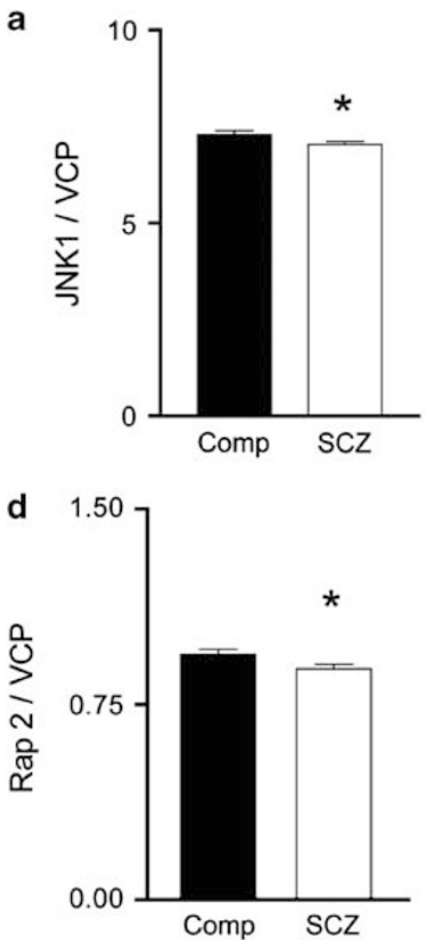

b
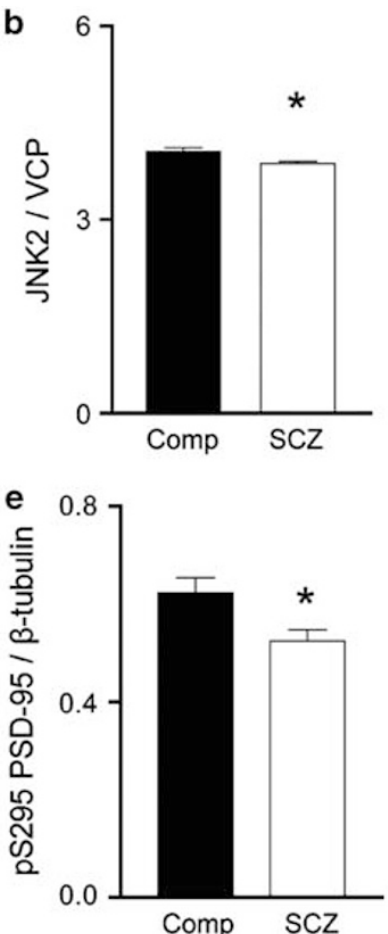

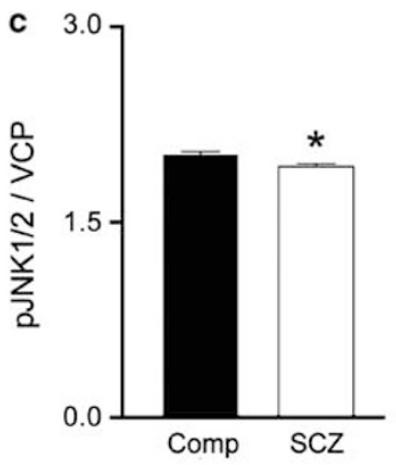

f

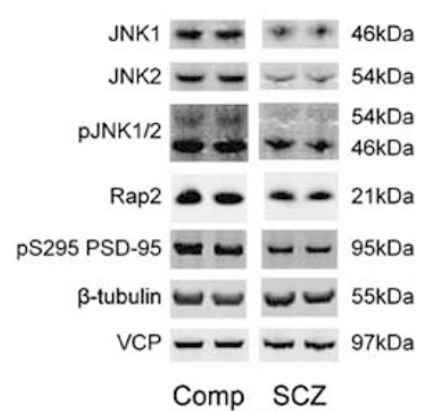

Figure I Intracellular signaling abnormalities of the ACC in schizophrenia. Decreased JNKI and JNK2 expression were found in schizophrenia (a, b). Dual phosphorylation of JNKI/2 at TI83/YI85 (c), Rap2 expression (d), and phosphorylation of PSD-95 at S295 (e) were all decreased in schizophrenia. Representative immunoblots (f). Data are means \pm SEM. ${ }^{*} p<0.05$. 

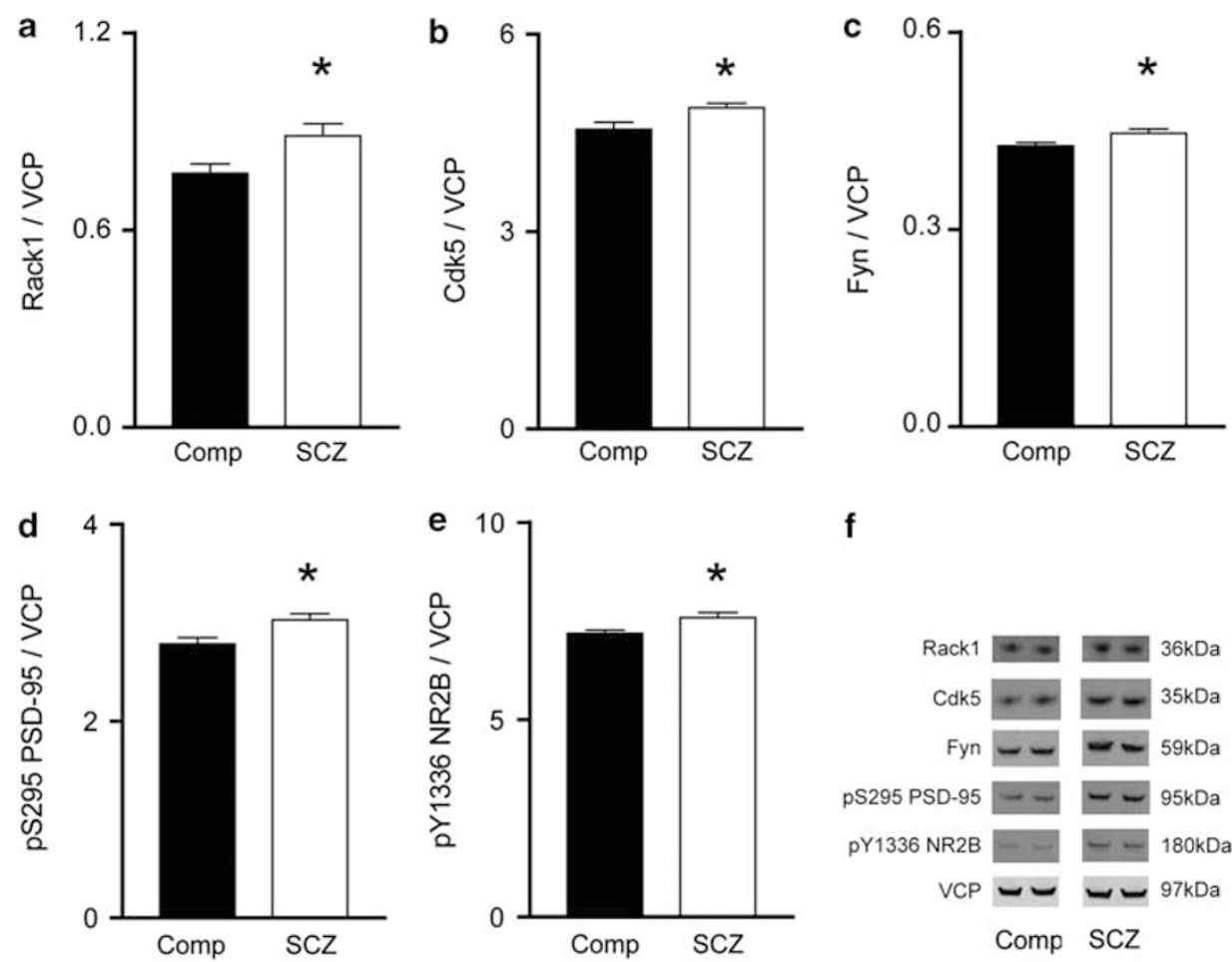

\section{f}

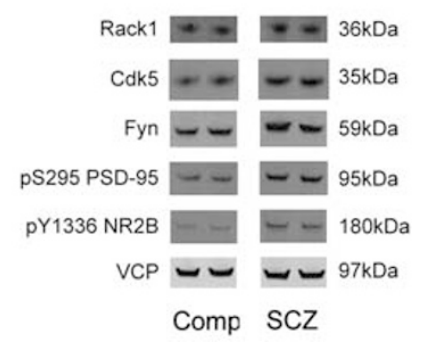

Figure 2 Intracellular signaling abnormalities of the DLPFC in schizophrenia. Increased expression of RackI and Fyn (a, c), Cdk5 (b), and phosphorylation of PSD-95 at serine 295 and NR2B at tyrosine 1336 (d, e) were seen in schizophrenia. Representative immunoblots (f). Data are means \pm SEM. *p<0.05.

(DARPP-32), which integrates signaling of glutamate, dopamine, serotonin, GABA, and other neurotransmitter families (Svenningsson et al, 2004). DARPP-32 knockout mice exhibit abnormalities of neurotransmitter receptor conductance and phosphorylation, synaptic plasticity, and immediate early gene and transcription factor activation (Svenningsson et al, 2004). These findings have been interpreted to suggest that integration of receptor signaling is critical for learning, memory, and executive functioning, which are often impaired in psychiatric illness. Although DARPP-32 is particularly well studied, there are many other kinases and effector molecules that finely tune input, output, and crosstalk between multiple neurotransmitter systems. In this study, we found region-specific changes in multiple intracellular pathways that integrate signaling of neurotransmitter systems previously reported to be dysregulated in schizophrenia, supporting a hypothesis that neuronal signal integration may be altered in this illness (Figure 3).

A growing literature implicates intracellular signaling abnormalities in schizophrenia (Kyosseva et al, 1999). Previous studies of the MAPK-associated pathway found changes in several constituent proteins. For example, both protein and transcript levels of ERK2, c-fos, and c-Jun were increased in the thalamus, whereas c-Jun protein and Elk-1, CREB, and ATF-2 protein levels and transcripts were noted to be increased in the cerebellar vermis (Kyosseva, 2004a; Kyosseva et al, 2000; Todorova et al, 2003). Other proteins of the MAPK pathway including MEK1, MEK2, RSK1, B-Raf, and CREB were decreased in the frontal cortex (Yuan et al, 2010). Although these earlier data support a hypothesis that MAPK-associated signaling is altered in schizophrenia, functional phosphorylation states and downstream phosphorylation targets were not assessed in these studies. In our study, we found a decrease in the dual phosphorylation state of JNK in the ACC in schizophrenia, which is a wellcharacterized proxy for JNK activity (Davis, 1999; Ip and Davis, 1998; Minden et al, 1994), suggesting that JNK activity is decreased in these subjects (Figure 1). We also evaluated several targets of JNK-mediated phosphorylation, to assess the potential functional relevance of decreased JNK activation. We found decreased pS295 PSD-95 in the ACC (Figure 1), consistent with decreased JNK activity (Figure 3). Decreased phosphorylation at S295 of PSD-95 suggests less PSD-95 targeted to synaptic sites (Kim et al, 2007), indicating impairment of glutamate neurotransmission in schizophrenia.

Abnormalities have been reported in cAMP-associated pathways in schizophrenia as well. For example, decreased DARPP-32 was detected in the frontal cortex and thalamus (Albert et al, 2002; Feldcamp et al, 2008; Ishikawa et al, 2007; Torres et al, 2009; Zhan et al, 2011), whereas transcripts for calcyon and spinophilin, mediators of dopaminergic signal integration, were increased in the thalamus in schizophrenia (Baracskay et al, 2006; Clinton et al, 2005). Additionally, phosphorylation of the N-methyl-D-aspartic acid (NMDA) receptor type 1 subunit at S897, a target of PKA, is decreased in the frontal cortex, suggesting fewer NMDA receptors at the synapse (Emamian et al, 2004; Tingley et al, 1997).

Increasing evidence implicates NMDA receptor dysregulation in schizophrenia, initially based on clinical evidence that non-competitive antagonists of N-methyl-D-aspartic acid receptors can be psychomimetic (Allen and Young, 


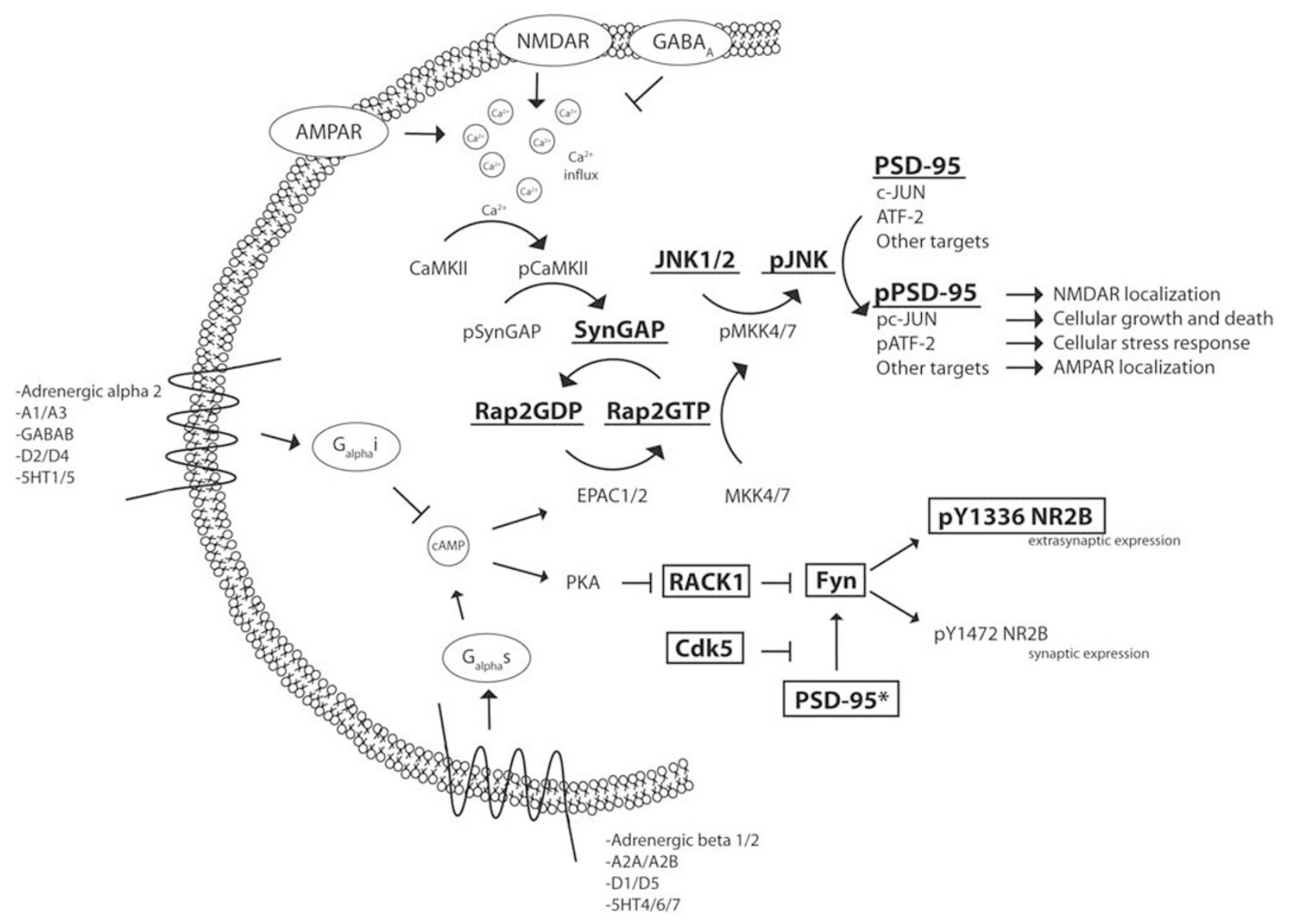

Figure 3 Dysregulation of convergent intracellular signaling pathways in frontal cortical regions in schizophrenia. Significant alterations found in the ACC and DLPFC are bolded and underlined or bolded and boxed, respectively. Downstream pathways of neurotransmitter systems known to be disturbed in schizophrenia converge upon common intracellular signaling pathways. Our data reflect abnormal protein expression and phosphorylation of key intracellular signaling molecules in both cortical regions. *A phosphorylated state of PSD-95 (pS295).

1978; Kristiansen et al, 2007; Lahti et al, 1995a, b, 2001; Luby et al, 1959; Meador-Woodruff and Healy, 2000; Svenningsson et al, 2003). Our present data suggest dysregulated localization and function of NMDA receptors. For example, increased phosphorylation of Y1336 NR2B, which targets NMDARs to extrasynaptic sites, suggests abnormal localization of NMDARs in the DLPFC (Figure 2) (Goebel-Goody et al, 2009; Zhu et al, 2005). This is consistent with the finding of decreased phospho-NR1, suggesting decreased NMDA receptors or altered subunit stoichiometry at synaptic sites (Emamian et al, 2004). Increased phosphorylation of NR2B at Y1336 may also confer abnormalities of LTP induction (Gardoni et al, 2009; Goebel-Goody et al, 2009).

Synaptic $v s$ extrasynaptic location of NMDARs critically alters receptor function and signaling pathway activation (Groc et al, 2009; Hardingham and Bading, 2010; Hardingham et al, 2002; Ivanov et al, 2006; Lau and Zukin, 2007). Extrasynaptic NR2B-containing NMDARs regulate NR2A function, potentially altering synapse development and plasticity (Kollen et al, 2008; Zhu et al, 2005). Consistent with abnormal synaptic NMDAR composition and the potential impact on plasticity, subunit specific transcript studies show decreased NR2D expression in multiple regions in schizophrenia (Harney et al, 2008). Alterations in proteins that modulate NR2-PSD-95 interactions may also impact synaptic structure and NMDAR function. For example, Rack1 is dissociated from the C-termini of NR2 subunits via activated PKA, permitting phosphorylation by Fyn and other Srk family kinases in a PSD-95-dependent manner (Cheng et al, 2008; Thornton et al, 2004; Yaka et al, 2002). Cdk5 can modulate Reelin and PSD-95/Fyn interactions (Beffert et al, 2004; Hawasli et al, 2007; Morabito et al, 2004; Ohshima et al, 2007; Xie et al, 2007a; Zhang et al, 2008). Thus, increased expression of Rack1, Cdk5, and Fyn suggests altered modulation of NMDAR-PSD-95 interactions at synaptic sites (Figure 2). The net effect of altered NMDAR-PSD-95 interactions may be decreased neurotransmission and signal integration at excitatory synapses in the DLPFC, functionally consistent with the result of changes found in the ACC (Figure 3).

In addition to NMDA abnormalities in schizophrenia, the AMPA receptor has also been implicated in the pathophysiology of this disorder (Dracheva et al, 2005; Hammond et al, 2010; Meador-Woodruff et al, 2001; O'Connor et al, 2007). Previously, we reported increased expression of the AMPAR associated proteins SAP97 and GRIP1 in the brain, as well as an increase in GluR1 AMPAR protein subunit expression in endosomes in the DLPFC (Hammond et al, 2010). Increased phosphorylation of PSD-95 at S295 reduces 
AMPAR internalization from the synapse and results in inhibition of LTD (Kim et al, 2007). Thus, increased phosphorylation of PSD-95 (Figure 2), in combination with increased SAP97 and GRIP1, suggests accelerated forward trafficking of AMPA receptors to synaptic sites. In the ACC, we found decreased phosphorylation of PSD-95 at S295 (Figure 1). Serine 295 is a target of JNK, phosphorylation of which induces localization of PSD-95 to synaptic sites (Kim et al, 2007). Thus, our data suggest less synapticallylocalized PSD-95, which may induce AMPAR internalization and induction of LTD in the ACC (Kim et al, 2007). Additionally, Rap2, a member of the Ras family of GTPases, indirectly activates JNK (Figure 3), and Rap2-JNK interactions traffic AMPA receptors away from the synapse during LTD, or bidirectionally in an activity dependent manner (Hussain et al, 2010; Thomas et al, 2008; Zhu et al, 2005). Interestingly, Rap2 function is modulated by SynGAP, a Ras and Rap GTPase-activating-protein, by its C2 domain (Funk et al, 2009; Pena et al, 2008). Recently reported decreases in SynGAP (Funk et al, 2009), together with decreased expression of Rap2, JNK1/2, and PSD-95, suggests abnormal AMPAR localization and trafficking in schizophrenia.

Genetic studies in schizophrenia also support a hypothesis that intracellular signaling may be involved in the pathophysiology of this illness. Genes implicated in schizophrenia include candidates associated with neurodevelopment (DISC-1, DTNBP1, and NOTCH4), synapse structure and formation (NRG1, NRXN1, PDE4B, APOE, and RELN), neurotransmitter synthesis and regulation (COMT, DAOA, and PRODH), and receptor and intracellular signaling (AKT1, DRD2, ERBB4, GABRB2, GRIN2B, HTR2A, and RGS4) (Tiwari et al, 2010). Polymorphisms in DLG4 (PSD-95) have recently been linked with schizophrenia, further implicating synaptic structure, neurotransmission, and intracellular signaling (Cheng et al, 2010). Such genetic associations increasingly support the hypothesis of dysregulated intracellular signaling pathways in schizophrenia.

In this study, we found region-specific alterations of proteins associated with the MAPK and cAMP intracellular signaling pathways. Regional differences in molecular abnormalities in schizophrenia are consistently reported in the literature (Katsel et al, 2005a,b; Kristiansen et al, 2006, 2010; Oni-Orisan et al, 2008), and although the sets of changes we found differed by cortical region, each set is functionally similar, resulting in decreased signal integration in both regions. This differential expression pattern may be inherent to the physiological circuits and inputs for each region. For example, connectivity deficits between the DLPFC and other neocortical structures have been well documented, where abnormal DLPFC activation significantly correlates with other cortical regions (Eisenberg and Berman, 2010). Additionally, communication between the ACC and DLPFC appears to be abnormal. ACC projections to the supragranular layers of the DLPFC are implicated because of their greater inhibition of the DLPFC (Eisenberg and Berman, 2010). Thus, the inherent connectivity and input of each region may be the mitigating factor behind the differential findings.

The changes we found are of small to moderate effect size, yet the consistent pattern of changes in sequential proteins in each pathway suggests that these abnormalities may be more physiologically relevant than the modest effect sizes for each protein might otherwise suggest. In fact, relatively small changes are perhaps not unexpected, as more substantial changes in expression of these proteins are associated with oncogenic, apoptotic, and excitotoxic events (Huang et al, 2009; Kim and Choi, 2010; Soriano et al, 2008; von Engelhardt et al, 2007; Wagner and Nebreda, 2009).

This study used well-characterized elderly subjects, and extrapolation of these findings to younger patients should be made with caution (Akbarian and Huang, 2006; Davidson et al, 1995; Deep-Soboslay et al, 2011; Harvey et al, 1992, 2010; Powchik et al, 1998). Additionally, we could not analyze the potential impact of differential freezer storage time among subjects in this cohort, as that data is unavailable. Other potential limitations to this work include the possibility that antipsychotic treatment can affect these signaling molecules (Bjarnadottir et al, 2007; Leveque et al, 2000). Post-hoc analysis for medication status, however, revealed no differences between subjects with schizophrenia who had been free of antipsychotic medication for at least 6 weeks before death compared with subjects with schizophrenia on medication at time of death, suggesting that these changes are associated with the illness and not because ofto the past treatment.

Although we have attempted to address a lifetime of antipsychotic use, these observations do not discount the possibility that medication may alter these signaling pathways. Indeed, animal studies have demonstrated that signaling molecules are targets of modification with antipsychotic treatment. Proteins downstream of cAMP- and MAPKassociated pathways are changed after acute and chronic antipsychotic treatment (Ahmed et al, 2008; Molteni et al, 2009). Additionally, the pharmacological activity of nicotine has been shown to act via these same signaling pathways (Mobascher and Winterer, 2008). As the majority of patients with schizophrenia smoke cigarettes, nicotine may contribute to changes in signaling pathways with respect to the comparison group (Winterer, 2010).

The proteins that we have studied occupy a unique position, linking myriad neurotransmitter systems that have been implicated in the pathophysiology of schizophrenia. Our data suggest convergent pathways common to the many neurotransmitter receptors dysregulated in schizophrenia are also disturbed in this illness. Convergence of specific neurotransmitter systems onto dysregulated intracellular signaling pathways may be a final common pathway associated with the pathophysiology of schizophrenia.

\section{ACKNOWLEDGEMENTS}

This work was supported by MH53327 (JMW), MH064673 and MH066392 (VH), MH074016, and Doris Duke Clinical Scientist Award (REM).

\section{DISCLOSURE}

Dr James $\mathrm{H}$ Meador-Woodruff receives an honorarium as editor of Neuropsychopharmacology. The other authors declare no conflict of interest. 


\section{REFERENCES}

Ahmed MR, Gurevich VV, Dalby KN, Benovic JL, Gurevich EV (2008). Haloperidol and clozapine differentially affect the expression of arrestins, receptor kinases, and extracellular signal-regulated kinase activation. J Pharmacol Exp Ther 325: 276-283.

Akbarian S, Huang HS (2006). Molecular and cellular mechanisms of altered GAD1/GAD67 expression in schizophrenia and related disorders. Brain Res Rev 52: 293-304.

Albert KA, Hemmings HC, Adamo AI, Potkin SG, Akbarian S, Sandman CA et al (2002). Evidence for decreased DARPP-32 in the prefrontal cortex of patients with schizophrenia. Arch Gen Psychiatry 59: 705-712.

Allen R, Young S (1978). Phencyclidine-induced psychosis. Am J Psychiatry 135: 1081-1084.

Baracskay KL, Haroutunian V, Meador-Woodruff JH (2006). Dopamine receptor signaling molecules are altered in elderly schizophrenic cortex. Synapse 60: 271-279.

Bauer D, Gupta D, Harotunian V, Meador-Woodruff J, McCullumsmith R (2008). Abnormal expression of glutamate transporter and transporter interacting molecules in prefrontal cortex in elderly patients with schizophrenia. Schizophr Res 104: 108-120.

Bauer D, Haroutunian V, McCullumsmith R, Meador-Woodruff J (2009). Expression of four housekeeping proteins in elderly patients with schizophrenia. J Neural Transm 116: 487-491.

Bauer D, Haroutunian V, Meador-Woodruff J, McCullumsmith R (2010). Abnormal glycosylation of EAAT1 and EAAT2 in prefrontal cortex of elderly patients with schizophrenia. Schizophr Res 117: 92-98.

Beffert U, Weeber E, Morfini G, Ko J, Brady S, Tsai L et al (2004). Reelin and cyclin-dependent kinase 5-dependent signals cooperate in regulating neuronal migration and synaptic transmission. J Neurosci 24: 1897-1906.

Bjarnadottir M, Misner DL, Haverfield-Gross S, Bruun S, Helgason VG, Stefansson $\mathrm{H}$ et al (2007). Neuregulin1 (NRG1) signaling through Fyn modulates NMDA receptor phosphorylation: differential synaptic function in NRG1+/- knock-outs compared with wild-type mice. J Neurosci 27: 4519-4529.

Bogoyevitch M, Ngoei K, Zhao T, Yeap Y, Ng D (2010). c-Jun $\mathrm{N}$-terminal kinase (JNK) signaling: recent advances and challenges. Biochim Biophys Acta 1804: 463-475.

Borland G, Smith B, Yarwood S (2009). EPAC proteins transduce diverse cellular actions of cAMP. Br J Pharmacol 158: 70-86.

Cheng MC, Lu CL, Luu SU, Tsai HM, Hsu SH, Chen TT et al (2010). Genetic and functional analysis of the DLG4 gene encoding the post-synaptic density protein 95 in schizophrenia. PLoS One 5: e15107.

Cheng X, Ji Z, Tsalkova T, Mei F (2008). Epac and PKA: a tale of two intracellular cAMP receptors. Acta Biochim Biophys Sin (Shanghai) 40: 651-662.

Clinton SM, Ibrahim HM, Frey KA, Davis KL, Haroutunian V, Meador-Woodruff JH (2005). Dopaminergic abnormalities in select thalamic nuclei in schizophrenia: involvement of the intracellular signal integrating proteins calcyon and spinophilin. Am J Psychiatry 162: 1859-1871.

Davidson M, Harvey PD, Powchik P, Parrella M, White L, Knobler HY et al (1995). Severity of symptoms in chronically institutionalized geriatric schizophrenic patients. Am J Psychiatry 152: 197-207.

Davis R (1999). Signal transduction by the c-Jun N-terminal kinase. Biochem Soc Symp 64: 1-12.

Deep-Soboslay A, Benes FM, Haroutunian V, Ellis JK, Kleinman JE, Hyde TM (2011). Psychiatric brain banking: three perspectives on current trends and future directions. Biol Psychiatry 69: 104-112.

Dracheva S, McGurk SR, Haroutunian V (2005). mRNA expression of AMPA receptors and AMPA receptor binding proteins in the cerebral cortex of elderly schizophrenics. J Neurosci Res 79: 868-878.

Dunah A, Sirianni A, Fienberg A, Bastia E, Schwarzschild M, Standaert D (2004). Dopamine D1-dependent trafficking of striatal N-methyl-D-aspartate glutamate receptors requires Fyn protein tyrosine kinase but not DARPP-32. Mol Pharmacol 65: 121-129.

Eisenberg DP, Berman KF (2010). Executive function, neural circuitry, and genetic mechanisms in schizophrenia. Neuropsychopharmacology 35: 258-277.

Emamian E, Karayiorgou M, Gogos J (2004). Decreased phosphorylation of NMDA receptor type 1 at serine 897 in brains of patients with Schizophrenia. J Neurosci 24: 1561-1564.

Fatemi S, Folsom T (2009). The neurodevelopmental hypothesis of schizophrenia, revisited. Schizophr Bull 35: 528-548.

Feldcamp LA, Souza RP, Romano-Silva M, Kennedy JL, Wong AH (2008). Reduced prefrontal cortex DARPP-32 mRNA in completed suicide victims with schizophrenia. Schizophr Res 103: 192-200.

Funk A, Rumbaugh G, Harotunian V, McCullumsmith R, Meador-Woodruff J (2009). Decreased expression of NMDA receptor-associated proteins in frontal cortex of elderly patients with schizophrenia. Neuroreport 20: 1019-1022.

Gardoni F, Mauceri D, Malinverno M, Polli F, Costa C, Tozzi A et al (2009). Decreased NR2B subunit synaptic levels cause impaired long-term potentiation but not long-term depression. J Neurosci 29: 669-677.

Gardoni F, Polli F, Cattabeni F, Di Luca M (2006). Calciumcalmodulin-dependent protein kinase II phosphorylation modulates PSD-95 binding to NMDA receptors. Eur J Neurosci 24: 2694-2704.

Gelinas J, Banko J, Peters M, Klann E, Weeber E, Nguyen P (2008). Activation of exchange protein activated by cyclic-AMP enhances long-lasting synaptic potentiation in the hippocampus. Learn Mem 15: 403-411.

Goebel-Goody SM, Davies KD, Alvestad Linger RM, Freund RK, Browning MD (2009). Phospho-regulation of synaptic and extrasynaptic N-methyl-d-aspartate receptors in adult hippocampal slices. Neuroscience 158: 1446-1459.

Groc L, Bard L, Choquet D (2009). Surface trafficking of N-methylD-aspartate receptors: physiological and pathological perspectives. Neuroscience 158: 4-18.

Hammond J, McCullumsmith R, Funk A, Haroutunian V, Meador-Woodruff J (2010). Evidence for abnormal forward trafficking of AMPA receptors in frontal cortex of elderly patients with schizophrenia. Neuropsychopharmacology 35: 2110-2119.

Hardingham GE, Bading H (2010). Synaptic vs extrasynaptic NMDA receptor signalling: implications for neurodegenerative disorders. Nat Rev Neurosci 11: 682-696.

Hardingham GE, Fukunaga Y, Bading H (2002). Extrasynaptic NMDARs oppose synaptic NMDARs by triggering CREB shut-off and cell death pathways. Nat Neurosci 5: 405-414.

Harney SC, Jane DE, Anwyl R (2008). Extrasynaptic NR2Dcontaining NMDARs are recruited to the synapse during LTP of NMDAR-EPSCs. J Neurosci 28: 11685-11694.

Harvey PD, Davidson M, Powchik P, Parrella M, White L, Mohs RC (1992). Assessment of dementia in elderly schizophrenics with structured rating scales. Schizophr Res 7: 85-90.

Harvey PD, Reichenberg A, Bowie CR, Patterson TL, Heaton RK (2010). The course of neuropsychological performance and functional capacity in older patients with schizophrenia: influences of previous history of long-term institutional stay. Biol Psychiatry 67: 933-939.

Hawasli A, Benavides D, Nguyen C, Kansy J, Hayashi K, Chambon $\mathrm{P}$ et al (2007). Cyclin-dependent kinase 5 governs learning and synaptic plasticity via control of NMDAR degradation. Nat Neurosci 10: 880-886. 
Hochbaum D, Hong K, Barila G, Ribeiro-Neto F, Altschuler D (2008). Epac, in synergy with cAMP-dependent protein kinase (PKA), is required for cAMP-mediated mitogenesis. J Biol Chem 283: 4464-4468.

Hosokawa T, Saito T, Asada A, Ohshima T, Itakura M, Takahashi $\mathrm{M}$ et al (2006). Enhanced activation of Ca2+/calmodulindependent protein kinase II upon downregulation of cyclindependent kinase 5-p35. J Neurosci Res 84: 747-754.

Huang G, Shi LZ, Chi H (2009). Regulation of JNK and p38 MAPK in the immune system: signal integration, propagation and termination. Cytokine 48: 161-169.

Hussain NK, Hsin H, Huganir RL, Sheng M (2010). MINK and TNIK differentially act on Rap2-mediated signal transduction to regulate neuronal structure and AMPA receptor function. $J$ Neurosci 30: 14786-14794.

Ip Y, Davis R (1998). Signal transduction by the c-Jun N-terminal kinase (JNK) - from inflammation to development. Curr Opin Cell Biol 10: 205-219.

Ishikawa M, Mizukami K, Iwakiri M, Asada T (2007). Immunohistochemical and immunoblot analysis of Dopamine and cyclic AMP-regulated phosphoprotein, relative molecular mass 32,000 (DARPP-32) in the prefrontal cortex of subjects with schizophrenia and bipolar disorder. Prog Neuropsychopharmacol Biol Psychiatry 31: 1177-1181.

Ivanov A, Pellegrino C, Rama S, Dumalska I, Salyha Y, Ben-Ari Y et al (2006). Opposing role of synaptic and extrasynaptic NMDA receptors in regulation of the extracellular signal-regulated kinases (ERK) activity in cultured rat hippocampal neurons. J Physiol 572(Pt 3): 789-798.

Katsel P, Davis KL, Gorman JM, Haroutunian V (2005a). Variations in differential gene expression patterns across multiple brain regions in schizophrenia. Schizophr Res 77: 241-252.

Katsel P, Davis KL, Haroutunian V (2005b). Variations in myelin and oligodendrocyte-related gene expression across multiple brain regions in schizophrenia: a gene ontology study. Schizophr Res 79: 157-173.

Kim E, Choi E (2010). Pathological roles of MAPK signaling pathways in human diseases. Biochim Biophys Acta 1802: 396-405.

Kim M, Futai K, Jo J, Hayashi Y, Cho K, Sheng M (2007). Synaptic accumulation of PSD-95 and synaptic function regulated by phosphorylation of serine-295 of PSD-95. Neuron 56: 488-502.

Kollen M, Dutar P, Jouvenceau A (2008). The magnitude of hippocampal long term depression depends on the synaptic location of activated NR2-containing N-methyl-D-aspartate receptors. Neuroscience 154: 1308-1317.

Krapivinsky G, Medina I, Krapivinsky L, Gapon S, Clapham D (2004). SynGAP-MUPP1-CaMKII synaptic complexes regulate p38 MAP kinase activity and NMDA receptor-dependent synaptic AMPA receptor potentiation. Neuron 43: 563-574.

Kristiansen L, Beneyto M, Haroutunian V, Meador-Woodruff J (2006). Changes in NMDA receptor subunits and interacting PSD proteins in dorsolateral prefrontal and anterior cingulate cortex indicate abnormal regional expression in schizophrenia. Mol Psychiatry 11: 737-747, 705.

Kristiansen L, Huerta I, Beneyto M, Meador-Woodruff J (2007). NMDA receptors and schizophrenia. Curr Opin Pharmacol 7: 48-55.

Kristiansen L, Patel S, Haroutunian V, Meador-Woodruff J (2010). Expression of the NR2B-NMDA receptor subunit and its Tbr-1/ CINAP regulatory proteins in postmortem brain suggest altered receptor processing in schizophrenia. Synapse 64: 495-502.

Kyosseva S (2004a). Differential expression of mitogen-activated protein kinases and immediate early genes fos and jun in thalamus in schizophrenia. Prog Neuropsychopharmacol Biol Psychiatry 28: 997-1006.

Kyosseva S (2004b). Mitogen-activated protein kinase signaling. Int Rev Neurobiol 59: 201-220.
Kyosseva S, Elbein A, Griffin W, Mrak R, Lyon M, Karson C (1999). Mitogen-activated protein kinases in schizophrenia. Biol Psychiatry 46: 689-696.

Kyosseva S, Elbein A, Hutton T, Griffin S, Mrak R, Sturner W et al (2000). Increased levels of transcription factors Elk-1, cyclic adenosine monophosphate response element-binding protein, and activating transcription factor 2 in the cerebellar vermis of schizophrenic patients. Arch Gen Psychiatry 57: 685-691.

Lahti A, Holcomb H, Medoff D, Tamminga C (1995a). Ketamine activates psychosis and alters limbic blood flow in schizophrenia. Neuroreport 6: 869-872.

Lahti A, Koffel B, LaPorte D, Tamminga C (1995b). Subanesthetic doses of ketamine stimulate psychosis in schizophrenia. Neuropsychopharmacology 13: 9-19.

Lahti A, Weiler M, Tamara Michaelidis B, Parwani A, Tamminga C (2001). Effects of ketamine in normal and schizophrenic volunteers. Neuropsychopharmacology 25: 455-467.

Lang U, Puls I, Muller D, Strutz-Seebohm N, Gallinat J (2007). Molecular mechanisms of schizophrenia. Cell Physiol Biochem 20: $687-702$.

Laruelle M, Kegeles L, Abi-Dargham A (2003). Glutamate, dopamine, and schizophrenia: from pathophysiology to treatment. Ann N Y Acad Sci 1003: 138-158.

Lau C, Zukin R (2007). NMDA receptor trafficking in synaptic plasticity and neuropsychiatric disorders. Nat Rev Neurosci 8: 413-426.

Leveque JC, Macías W, Rajadhyaksha A, Carlson RR, Barczak A, Kang $S$ et al (2000). Intracellular modulation of NMDA receptor function by antipsychotic drugs. J Neurosci 20: 4011-4020.

Lewis DA, Hashimoto T (2007). Deciphering the disease process of schizophrenia: the contribution of cortical GABA neurons. Int Rev Neurobiol 78: 109-131.

Lewis DA, Moghaddam B (2006). Cognitive dysfunction in schizophrenia: convergence of gamma-aminobutyric acid and glutamate alterations. Arch Neurol 63: 1372-1376.

Lowes VL, Ip NY, Wong YH (2002). Integration of signals from receptor tyrosine kinases and $\mathrm{g}$ protein-coupled receptors. Neurosignals 11: 5-19.

Luby E, Cohen B, Rosenbaum G, Gottlieb J, Kelley R (1959). Study of a new schizophrenomimetic drug; sernyl. AMA Arch Neurol Psychiatry 81: 363-369.

Ma N, Abel T, Hernandez P (2009). Exchange protein activated by cAMP enhances long-term memory formation independent of protein kinase A. Learn Mem 16: 367-370.

MacDonald A, Schulz S (2009). What we know: findings that every theory of schizophrenia should explain. Schizophr Bull 35: 493-508.

Mauceri D, Gardoni F, Marcello E, Di Luca M (2007). Dual role of CaMKII-dependent SAP97 phosphorylation in mediating trafficking and insertion of NMDA receptor subunit NR2A. J Neurochem 100: 1032-1046.

Meador-Woodruff J, Healy D (2000). Glutamate receptor expression in schizophrenic brain. Brain Res Brain Res Rev 31: 288-294.

Meador-Woodruff J, Hogg AJ, Smith R (2001). Striatal ionotropic glutamate receptor expression in schizophrenia, bipolar disorder, and major depressive disorder. Brain Res Bull 55: 631-640.

Minden A, Lin A, Smeal T, Dérijard B, Cobb M, Davis R et al (1994). c-Jun N-terminal phosphorylation correlates with activation of the JNK subgroup but not the ERK subgroup of mitogen-activated protein kinases. Mol Cell Biol 14: 6683-6688.

Mobascher A, Winterer G (2008). The molecular and cellular neurobiology of nicotine abuse in schizophrenia. Pharmacopsychiatry 41(Suppl 1): S51-S59.

Molteni R, Calabrese F, Racagni G, Fumagalli F, Riva MA (2009). Antipsychotic drug actions on gene modulation and signaling mechanisms. Pharmacol Ther 124: 74-85. 
Morabito M, Sheng M, Tsai L (2004). Cyclin-dependent kinase 5 phosphorylates the $\mathrm{N}$-terminal domain of the postsynaptic density protein PSD-95 in neurons. J Neurosci 24: 865-876.

O'Connor JA, Muly EC, Arnold SE, Hemby SE (2007). AMPA receptor subunit and splice variant expression in the DLPFC of schizophrenic subjects and rhesus monkeys chronically administered antipsychotic drugs. Schizophr Res 90: 28-40.

Ohshima T, Suzuki H, Morimura T, Ogawa M, Mikoshiba K (2007). Modulation of Reelin signaling by Cyclin-dependent kinase 5 . Brain Res 1140: 84-95.

Oni-Orisan A, Kristiansen L, Haroutunian V, Meador-Woodruff J, McCullumsmith R (2008). Altered vesicular glutamate transporter expression in the anterior cingulate cortex in schizophrenia. Biol Psychiatry 63: 766-775.

Pena V, Hothorn M, Eberth A, Kaschau N, Parret A, Gremer L et al (2008). The C2 domain of SynGAP is essential for stimulation of the Rap GTPase reaction. EMBO Rep 9: 350-355.

Powchik P, Davidson M, Haroutunian V, Gabriel SM, Purohit DP, Perl DP et al (1998). Postmortem studies in schizophrenia. Schizophr Bull 24: 325-341.

Reichenberg A (2010). The assessment of neuropsychological functioning in schizophrenia. Dialogues Clin Neurosci 12: 383-392.

Roberson ED, English JD, Adams JP, Selcher JC, Kondratick C, Sweatt JD (1999). The mitogen-activated protein kinase cascade couples PKA and PKC to cAMP response element binding protein phosphorylation in area CA1 of hippocampus. J Neurosci 19: 4337-4348.

Ross C, Margolis R, Reading S, Pletnikov M, Coyle J (2006). Neurobiology of schizophrenia. Neuron 52: 139-153.

Sands W, Palmer T (2008). Regulating gene transcription in response to cyclic AMP elevation. Cell Signal 20: 460-466.

Santucci D, Raghavachari S (2008). The effects of NR2 subunitdependent NMDA receptor kinetics on synaptic transmission and CaMKII activation. PLoS Comput Biol 4: e1000208.

Song B, Yan X, Zhang G (2004). PSD-95 promotes CaMKIIcatalyzed serine phosphorylation of the synaptic RAS-GTPase activating protein SynGAP after transient brain ischemia in rat hippocampus. Brain Res 1005: 44-50.

Soriano F, Martel M, Papadia S, Vaslin A, Baxter P, Rickman C et al (2008). Specific targeting of pro-death NMDA receptor signals with differing reliance on the NR2B PDZ ligand. J Neurosci 28: 10696-10710.

Stilo SA, Murray RM (2010). The epidemiology of schizophrenia: replacing dogma with knowledge. Dialogues Clin Neurosci 12: 305-315.

Svenningsson P, Nishi A, Fisone G, Girault JA, Nairn AC, Greengard P (2004). DARPP-32: an integrator of neurotransmission. Annu Rev Pharmacol Toxicol 44: 269-296.

Svenningsson P, Tzavara E, Carruthers R, Rachleff I, Wattler S, Nehls $M$ et al (2003). Diverse psychotomimetics act through a common signaling pathway. Science 302: 1412-1415.

Sweatt JD (2001). The neuronal MAP kinase cascade: a biochemical signal integration system subserving synaptic plasticity and memory. J Neurochem 76: 1-10.

Sweatt JD (2004). Mitogen-activated protein kinases in synaptic plasticity and memory. Curr Opin Neurobiol 14: 311-317.

Thomas G, Lin D, Nuriya M, Huganir R (2008). Rapid and bi-directional regulation of AMPA receptor phosphorylation and trafficking by JNK. EMBO J 27: 361-372.
Thornton C, Tang K, Phamluong K, Luong K, Vagts A, Nikanjam D et al (2004). Spatial and temporal regulation of RACK1 function and N-methyl-D-aspartate receptor activity through WD40 motif-mediated dimerization. J Biol Chem 279: 31357-31364.

Tingley WG, Ehlers MD, Kameyama K, Doherty C, Ptak JB, Riley CT et al (1997). Characterization of protein kinase A and protein kinase $\mathrm{C}$ phosphorylation of the $\mathrm{N}$-methyl-D-aspartate receptor NR1 subunit using phosphorylation site-specific antibodies. J Biol Chem 272: 5157-5166.

Tiwari AK, Zai CC, Müller DJ, Kennedy JL (2010). Genetics in schizophrenia: where are we and what next? Dialogues Clin Neurosci 12: 289-303.

Todorova V, Elbein A, Kyosseva S (2003). Increased expression of c-Jun transcription factor in cerebellar vermis of patients with schizophrenia. Neuropsychopharmacology 28: 1506-1514.

Torres KC, Souza BR, Miranda DM, Nicolato R, Neves FS, Barros AG et al (2009). The leukocytes expressing DARPP-32 are reduced in patients with schizophrenia and bipolar disorder. Prog Neuropsychopharmacol Biol Psychiatry 33: 214-219.

Volk DW, Eggan SM, Lewis DA (2010). Alterations in metabotropic glutamate receptor $1 \alpha$ and regulator of $G$ protein signaling 4 in the prefrontal cortex in schizophrenia. Am J Psychiatry 167: $1489-1498$.

von Engelhardt J, Coserea I, Pawlak V, Fuchs E, Köhr G, Seeburg $\mathrm{P}$ et al (2007). Excitotoxicity in vitro by NR2Aand NR2B-containing NMDA receptors. Neuropharmacology 53: $10-17$.

Wagner EF, Nebreda AR (2009). Signal integration by JNK and p38 MAPK pathways in cancer development. Nat Rev Cancer 9: 537-549.

Winterer G (2010). Why do patients with schizophrenia smoke? Curr Opin Psychiatry 23: 112-119.

Xie F, Padival M, Siegel R (2007a). Association of PSD-95 with ErbB4 facilitates neuregulin signaling in cerebellar granule neurons in culture. J Neurochem 100: 62-72.

Xie Z, Srivastava D, Photowala H, Kai L, Cahill M, Woolfrey K et al (2007b). Kalirin-7 controls activity-dependent structural and functional plasticity of dendritic spines. Neuron 56: 640-656.

Yaka R, Thornton C, Vagts A, Phamluong K, Bonci A, Ron D (2002). NMDA receptor function is regulated by the inhibitory scaffolding protein, RACK1. Proc Natl Acad Sci USA 99: 5710-5715.

Yuan P, Zhou R, Wang Y, Li X, Li J, Chen G et al (2010). Altered levels of extracellular signal-regulated kinase signaling proteins in postmortem frontal cortex of individuals with mood disorders and schizophrenia. J Affect Disord 124: 164-169.

Zarubin T, Han J (2005). Activation and signaling of the p38 MAP kinase pathway. Cell Res 15: 11-18.

Zhan L, Kerr JR, Lafuente MJ, Maclean A, Chibalina MV, Liu B et al (2011). Altered expression and coregulation of dopamine signalling genes in schizophrenia and bipolar disorder. Neuropathol Appl Neurobiol 37: 206-219.

Zhang S, Edelmann L, Liu J, Crandall J, Morabito M (2008). Cdk5 regulates the phosphorylation of tyrosine 1472 NR2B and the surface expression of NMDA receptors. J Neurosci 28: 415-424.

Zhu Y, Pak D, Qin Y, McCormack S, Kim M, Baumgart J et al (2005). Rap2-JNK removes synaptic AMPA receptors during depotentiation. Neuron 46: 905-916.

Supplementary Information accompanies the paper on the Neuropsychopharmacology website (http://www.nature.com/npp) 